\title{
Pregabalin Misuse and Abuse in Jordan
}

\section{Dr. Maxim A. Obiesat*, Dr. Muath F. Marashdeh, Dr. Arafat K Al-Zoubi, Dr. Malik M. Al-Alwan,}

\section{Dr. Raya T. Al-Odat}

\begin{abstract}
MD, Psychiatry, Jordanian Royal Medical Services, MD, Psychiatry, Jordanian Royal Medical Services, MD, Psychiatry, Jordanian Royal Medical Services, MD, Psychiatry, Jordanian Royal Medical Services, Pharmacist, Jordanian Royal Medical Services
\end{abstract}

\begin{abstract}
:
Pregabalin are widely used in neurology, psychiatry and primary healthcare for a range of clinical conditions but are increasingly being reported as possessing a potential for misuse. In fact, increasing levels of both prescriptions and related fatalities, together with an anecdotally growing black market, have been reported in Jordan.
\end{abstract}

\section{Objectives:}

The aim of the study was to identify and assess cases of Pregabalin misuse or dependence as reported to the Jordanian Mental health care clinics database, to identify the magnitude of this problem and the characteristics of these reactions and reviews the current evidence base of this potential, in an attempt to answer the question of whether there is cause for concern about this drug.

\section{Methods:}

All spontaneous reports of Pregabalin - (2016-2017) related misuse/abuse/dependence were retrieved. A descriptive analysis by source, sex, age, and type of report was performed.

\section{Introduction:}

Potent binding of pregabalin at the calcium channel results in a reduction in the release of excitatory molecules. Furthermore, gabapentinoids are thought to possess GABA-mimetic properties whilst possibly presenting with direct/indirect effects on the dopaminergic 'reward' system. Overall, pregabalin is characterized by higher potency, quicker absorption rates and greater bioavailability levels than other gabapentinoids. Although at therapeutic dosages gabapentinoids may present with low addictive liability levels, misusers perceptions for these molecules to constitute a valid substitute for most common illicit drugs may be a reason of concern. Gabapentinoid experimenters are profiled here as individuals with a history of recreational polydrug misuse, who self-administer with dosages clearly in excess (e.g. up to 3-20 times) of those that are clinically advisable. Physicians considering prescribing gabapentinoids for neurological/psychiatric disorders should carefully evaluate a possible previous history of drug abuse, whilst being able to promptly identify signs of pregabalin misuse and provide possible assistance in tapering off the medication.

\section{Results:}

From the Jordanian Mental health care clinics database $7639(6.6 \%$ of a total of 115,616$)$ and $4301(4.8 \%$ of 90,166) adverse drug reaction reports of misuse/abuse/dependence were, respectively, associated with pregabalin, with an overall reporting frequency increasing over time. For both molecules, subjects typically involved were female adults. A total of 27 and 86 fatalities, respectively, associated with pregabalin, and mostly in combination with other drugs, were identified. Analysis of proportional reporting ratios for drug 
abuse/dependence/intentional product misuse values seem to indicate that these adverse drug reactions were more frequently reported for pregabalin $(1.25,1.39$, and 1.58 , respectively) compared with other gabapentinoids.

\section{Discussion:}

The study provides us with a deeper overview about the problem of pregabalin misuse/abuse in Jordan from the perspectives of those affected by abuse and dependence. Users reported boosting the effect of pregabalin by combining it with other drugs and various sweet drinks. Different factors (e.g., lack of pharmacist awareness about pregabalin abuse and prospect for economic gain to income) complicate the role of medical stuff in Jordanian communities. The lack of detection in urine screening additionally facilitates abusers to continue on pregabalin. The lack of detection might be due to the variability of urinary detection times of abused drugs, and differentiating new drug use from residual drug excretion could be difficult, especially after repeated or chronic drug usage.

\section{Conclusions:}

Despite data collection/methodological approach limitations, the present data seem to suggest that pregabalin misuse may be a cause for concern, especially in patients with a history of substance misuse. Hence, healthcare professionals should be vigilant when prescribing these molecules.

To consider prescribing gabapentinoids for neurological/psychiatric disorders only and should be only by neurologist or psychiatrist with medical report showing indications, duration of expected management plan and regularly evaluate a possible misuse and provide possible assistance in tapering off the medication.

\section{References:}

1. Baird, C. R., Fox, P., \& Colvin, L. A. (2014). Gabapentinoid abuse in order to potentiate the effect of methadone: a survey among substance misusers. European Addiction Research, 20(3), 115118.CrossRef PubMed

2. Carrus, D., \& Schifano, F. (2012). Pregabalin misuse-related issues; intake of large dosages, drugsmoking allegations, and possible association with myositis: two case reports. Journal of Clinical Psychopharmacology, 32(6), 839-840.CrossRef PubMed

3. Casati, A., Sedefov, R., \& Pfeiffer-Gerschel, T. (2012). Misuse of medicines in the European Union: a systematic review of the literature. European Addiction Research, 18(5), 228-245.CrossRef $\underline{\text { PubMed }}$

4. Cooper, R. J. (2013). Over-the-counter medicine abuse-a review of the literature. Journal of Substance Use, 18(2), 82-107.CrossRef PubMed

5. Driot, D., Chicoulaa, B., Jouanjus, E., Dupouy, J., Oustric, S., \& Lapeyre-Mestre, M. (2016). Pregabalin use disorder and secondary nicotine dependence in a woman with no substance abuse history. Thérapie, 71(6), 575-578.CrossRef PubMed

6. Drug Enforcement Administration, Department of Justice. (2005). Schedules of controlled substances: placement of pregabalin into schedule V. Final rule. Federal Register, 70(144), 43633. Dum, J., Gramsch, C. H., \& Herz, A. (1983). Activation of hypothalamic $\beta$-endorphin pools by reward induced by highly palatable food. Pharmacology Biochemistry and Behavior, 18(3), 443447. CrossRef

7. Freynhagen, R., Backonja, M., Schug, S., Lyndon, G., Parsons, B., Watt, S., \& Behar, R. (2016). Pregabalin for the treatment of drug and alcohol withdrawal symptoms: a comprehensive review. CNS Drugs, 30, 1-10. $\underline{\text { CrossRef }}$ 
8. Getto, C. J., Fullerton, D. T., \& Carlson, I. H. (1984). Plasma immunoreactive beta-endorphin response to glucose ingestion in human obesity. Appetite, 5(4), 329-335.CrossRefPubMedGoogle $\underline{\text { Scholar }}$

9. Grosshans, M., Lemenager, T., Vollmert, C., Kaemmerer, N., Schreiner, R., Mutschler, J., ... \& Hermann, D. (2013). Pregabalin abuse among opiate addicted patients. European Journal of Clinical Pharmacology, 69(12), 2021-2025.

10. Haddad, L., Shotar, A., Umlauf, M., \& Al-Zyoud, S. (2010). Knowledge of substance abuse among high school students in Jordan. Journal of Transcultural Nursing, 21(2), 143-150.CrossRef PubMed

11. Hernandez, S. H., \& Nelson, L. S. (2010). Prescription drug abuse: insight into the epidemic. Clinical Pharmacology \& Therapeutics, 88(3), 307-317. CrossRef

12. Holsti, O. R. (1969). Content analysis for the social sciences and humanities. Reading: AddisonWesley.

13. Hughes, G. F., McElnay, J. C., Hughes, C. M., \& McKenna, P. (1999). Abuse/misuse of nonprescription drugs. Pharmacy World \& Science, 21(6), 251-255.CrossRef

14. Husserl, E. (1970). Logical investigation. New York: Humanities Press.

15. Jaber, D., Bulatova, N., Suyagh, M., Yousef, A. M., \& Wazaify, M. (2015). Knowledge, attitude and opinion of drug misuse and abuse by pharmacy students: a cross-sectional study in Jordan. Tropical Journal of Pharmaceutical Research, 14(8), 1501-1508.CrossRef

16. Jensen, C., Forlini, C., Partridge, B., \& Hall, W. (2016). Australian university students' coping strategies and use of pharmaceutical stimulants as cognitive enhancers. Frontiers in Psychology, 7, 277.PubMed PubMedCentral

17. Johnson, B. A., Cloninger, C. R., Roache, J. D., Bordnick, P. S., \& Ruiz, P. (2000). Age of onset as a discriminator between alcoholic subtypes in a treatment-seeking outpatient population. The American Journal on Addictions, 9(1), 17-27.CrossRef PubMed

18. Jordan Food and drug Administration (JFDA). (2014). Formal statement about the restricted dispensing of pregabalin in Jordan. Can be obtained from URL: http://www.jfda.jo/EchoBusV3.0/SystemAssets/ce7e7f71-3158-4f56-92bd 5ea766cbce16.jpg. Accessed June 11th 2016.

19. Jordan Food and drug Administration (JFDA). (2017). Formal statement about the restricted dispensing of pregabalin in Jordan. Can be obtained from URL: http://www.jfda.jo/EchoBusV3.0/SystemAssets/2f00f42e-427b-40ba-abf4 93adfb8c2ad6.jpg. Accessed May 10th 2017.

20. Kampov-Polevoy, A., Garbutt, J. C., \& Janowsky, D. (1997). Evidence of preference for a highconcentration sucrose solution in alcoholic men. American Journal of Psychiatry, 154(2), 269270.CrossRef PubMed

21. Lessenger, J. E., \& Feinberg, S. D. (2008). Abuse of prescription and over-the-counter medications. The Journal of the American Board of Family Medicine, 21(1), 45-54.CrossRef PubMed

22. Loftus, H., \& Wright, A. (2014). Potential misuse of pregabalin and gabapentin. BMJ, 348, g1290.CrossRef PubMed 
23. Millar, J., Sadasivan, S., Weatherup, N., \& Lutton, S. (2013). Lyrica nights-recreational pregabalin abuse in an urban emergency department. Emergency Medicine Journal, 30(10), 874-874.CrossRef

24. National Institute on Drug Abuse (NIDA). (2014). Commonly abused drugs charts. Retrieved from. https://www.drugabuse.gov/drugs-abuse/commonly-abused-drugscharts. Accessed May 10th 2017.

25. Palamar, J. J., \& Barratt, M. J. (2016). Synthetic cannabinoids: undesirable alternatives to natural marijuana. The American Journal of Drug and Alcohol Abuse, 42(4), 371373.CrossRefPubMedPubMedCentral

26. Papazisis, G., \& Tzachanis, D. (2014). Pregabalin's abuse potential: a mini review focusing on the pharmacological profile. International Journal of Clinical Pharmacology and Therapeutics, 52(8), 709-716. CrossRef PubMed

27. Papazisis, G., Garyfallos, G., Sardeli, C., \& Kouvelas, D. (2013). Pregabalin abuse after past substance-seeking behavior. International Journal of Clinical Pharmacology and Therapeutics, 51(5), 441-442.CrossRef PubMed

28. Schifano, F., D’Offizi, S., Piccione, M., Corazza, O., Deluca, P., Davey, Z., ... \& Mannonen, M. (2011). Is there a recreational misuse potential for pregabalin? Analysis of anecdotal online reports in comparison with related gabapentin and clonazepam data. Psychotherapy and Psychosomatics, 80(2), $118-122$.

29. Schjerning, O., Rosenzweig, M., Pottegård, A., Damkier, P., \& Nielsen, J. (2016). Abuse potential of pregabalin. CNS Drugs, 30(1), 9-25.CrossRef PubMed

30. Schwan, S., Sundström, A., Stjernberg, E., Hallberg, E., \& Hallberg, P. (2010). A signal for an abuse liability for pregabalin-results from the Swedish spontaneous adverse drug reaction reporting system. European Journal of Clinical Pharmacology, 66(9), 947-953.CrossRefPubMed

31. Spigset, O., \& Westin, A. A. (2013). Detection times of pregabalin in urine after illicit use: when should a positive specimen be considered a new intake? Therapeutic Drug Monitoring, 35(1), 137140.CrossRef PubMed

32. Van Hout, M. C., \& Hearne, E. (2017). User experiences of development of dependence on the synthetic cannabinoids, 5f-AKB48 and 5F-PB-22, and subsequent withdrawal syndromes. International Journal of Mental Health and Addiction, 15(3), 565-579.CrossRef

33. Van Hout, M. C., \& Wells, J. (2016). Is Captagon (fenethylline) helping to fuel the Syrian conflict? Addiction, 111(4), 748-749.CrossRefPubMed 